\title{
CHEMICAL AND RADIOLOGICAL CHARACTERISATION OF SANTOS ESTUARY SEDIMENTS
}

\author{
Silva, P. S. C.*, Mazzilli B. P.* and Favaro D. I. T. ** \\ *Departamento de Radioproteção Ambiental \\ **Laboratório de Análise Por Ativação \\ Instituto de Pesquisas Energéticas e Nucleares \\ Caixa Postal 11049, São Paulo, Brasil
}

\begin{abstract}
Samples from Santos Estuary, an industrial area located in São Paulo State, Southwest Brazil, were analysed by neutron activation analysis and gamma spectrometry for elements As, Ba, Br, Ce, Co, Cr, Cs, Eu, Fe, Hf, K, La, Lu, Na, Nd, Rb, Sb, Sc, Se, Sm, Ta, Tb, Th, U, $\mathrm{Yb}$ and $\mathrm{Zr}$, and radionuclides ${ }^{226} \mathrm{Ra},{ }^{228} \mathrm{Ra},{ }^{210} \mathrm{~Pb}$ and ${ }^{40} \mathrm{~K}$, with the intent of characterise and identify possible contaminated areas due to industrial activities. With this goal, the results were analysed by means of Pearson's correlation coefficient and using iron concentration as a reference to normalise the determined elements.
\end{abstract}

\section{INTRODUCTION}

Estuaries may accumulate material transported by rivers, including substances of natural or industrial origin, such as major, minor or trace elements. Industries like phosphoric acid and fertiliser producers, could also contribute to the enhancement of radioactive elements content in the environment, as shown by McNabb et al. (1979) and Periáñez and Leon (1993).

Santos estuary, located in São Paulo State, Southwest Brazil, and comprising three main counties (Santos, São Vicente and Cubatão), is considered one of the most important industrial regions of Brazil.

This work aims to determine the chemical and radiological composition of sediments samples collected along Santos Estuary and to evaluate possible contaminated areas.

\section{METHODOLOGY}

Heighten sediment samples were collected by Companhia Brasileira de Saneamento Básico (CETESB), in points showed in figure 1. All samples were analysed by neutron activation analysis (NAA), for determination of the following elements: As, Ba, Br, Ce, Co, $\mathrm{Cr}, \mathrm{Cs}, \mathrm{Eu}, \mathrm{Fe}, \mathrm{Hf}, \mathrm{K}, \mathrm{La}, \mathrm{Lu}, \mathrm{Na}, \mathrm{Nd}, \mathrm{Rb}, \mathrm{Sb}, \mathrm{Sc}, \mathrm{Se}, \mathrm{Sm}, \mathrm{Ta}, \mathrm{Tb}, \mathrm{Th}, \mathrm{U}, \mathrm{Yb}$ and Zr. The elements determination was made by irradiation of approximately $150 \mathrm{mg}$ of each sample, during 16 hours at a neutron flux of $10^{12} \mathrm{n} \cdot \mathrm{cm}^{-2} \mathrm{~s}^{-1}$, at Instituto de Pesquisas Energéticas e Nucleares (IPEN) research reactor IEA-R1. The induced radioactivity was measured with a Ge-hyperpure detector, Intertechnique, with $2.1 \mathrm{keV}$ resolution for the $1332 \mathrm{keV}{ }^{60} \mathrm{Co}$ photopeak. The concentration of the analysed elements was determined by comparing activities obtained in the sediment samples with standard materials Buffalo River Sediment (NIST-2704) and Soil-7 (IAEA).

Among the collected samples, 13 were analysed by gamma spectrometry for radionuclides determination $\left({ }^{226} \mathrm{Ra},{ }^{228} \mathrm{Ra},{ }^{210} \mathrm{~Pb}\right.$ and $\left.{ }^{40} \mathrm{~K}\right)$. For this determination samples were sealed in polyethylene containers for about four weeks prior to the measurement, in order to ensure that equilibrium has been reached between ${ }^{226} \mathrm{Ra}$ and its decay products of short halflife, ${ }^{214} \mathrm{Bi} \mathrm{e}{ }^{214} \mathrm{~Pb}$. The ${ }^{228} \mathrm{Ra}$ content of the samples was determined by measurement of ${ }^{228} \mathrm{Ac}$ photopeaks and the concentrations of ${ }^{210} \mathrm{~Pb}$ and ${ }^{40} \mathrm{~K}$ were carried out by measuring the activity of their own photopeaks. Samples were measured by using a Ge-hyperpure detector, EGNC 
15-190-R from Eurisys, with 15\% efficiency, during 60.000s. The detector was calibrated using natural soil and rock spiked with radionuclides certified by Amersham. The system background was obtained by measuring the same sample counting geometry for $300.000 \mathrm{~s}$. The gamma spectra obtained were analysed by using WinnerGamma program.

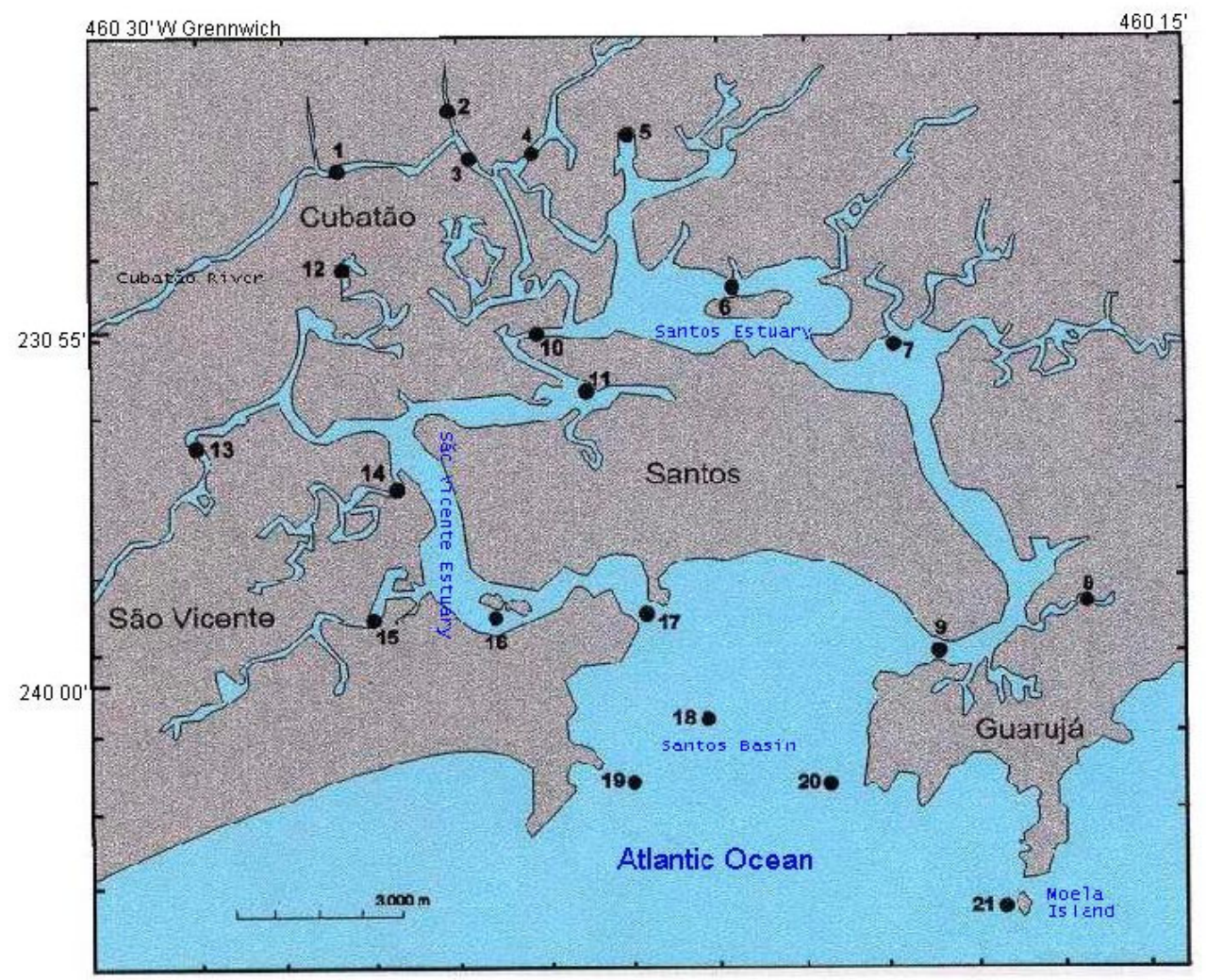

Figure 1: Santos estuary and location of the sampling points.

Self-absorption correction for ${ }^{210} \mathrm{~Pb}$ was applied since the attenuation for its low energy gamma rays is highly dependent upon sample composition. The approach used was modified from that suggested by Cutshall et al. (1983).

As organic matter is a good absorber of metals and radionuclides, its amount was also determined in the samples by heating at $360^{\circ} \mathrm{C}-370^{\circ} \mathrm{C}$ for 2 hours.

All sediment samples studied were prepared by drying at a temperature of $110^{\circ} \mathrm{C}$ to constant mass, ground to a grain-size of less than $250 \mu \mathrm{m}$ for gamma spectrometry, $105 \mu \mathrm{m}$ for NAA and finally homogenised.

\section{RESULTS AND CONCLUSIONS}

Table 1 shows the results obtained in the samples measurement by NAA, the mean values, the relative standard deviation and the range of values. It can be seen that the elements $\mathrm{Br}$ and $\mathrm{U}$ presented higher variations and $\mathrm{Ba}$ the smallest one, although for the majority of the analysed elements the variations obtained were bigger than $50 \%$, reflecting the complexity of this kind of environment.

Elbaz-Poulichet and Dupuy (1999) showed that phosphate deposits contribute to the enhancement of rare earth elements in the environment. In a previous paper, the same authors presented the concentration of rare earth elements in the same sediment samples (Silva et al., 
2001). An increase in rare earth elements was found in points 1, 2 and 3, probably due to their release together with $\mathrm{Th}$ and $\mathrm{Ra}$ isotopes from phosphogypsum stockpiled in the surrounding.

Table 1: Mean value, relative standard deviation and range obtained for sediments by NAA $(\mu \mathrm{g} / \mathrm{g}$, ).

\begin{tabular}{cccc}
\hline & mean & rsd & Range \\
\hline $\mathrm{As}$ & 6 & 61 & $2-11$ \\
\hline $\mathrm{Ba}$ & 329 & 27 & $116-488$ \\
\hline $\mathrm{Br}$ & 50 & 84 & $2-133$ \\
\hline $\mathrm{Ce}$ & 64 & 56 & $8-136$ \\
\hline $\mathrm{Co}$ & 6 & 50 & $1,3-12$ \\
\hline $\mathrm{Cr}$ & 35 & 55 & $7-78$ \\
\hline $\mathrm{Cs}$ & 3 & 56 & $0,5-8$ \\
\hline $\mathrm{Eu}$ & 0,9 & 39 & $0,2-1,5$ \\
\hline $\mathrm{Fe}(\%)$ & 2 & 49 & $0,4-4$ \\
\hline $\mathrm{Hf}$ & 6 & 62 & $1,2-13$ \\
\hline $\mathrm{K}(\%)$ & 1,2 & 40 & $0,4-1,8$ \\
\hline $\mathrm{La}$ & 28 & 61 & $6-65$ \\
\hline $\mathrm{Lu}$ & 0,3 & 54 & $0,04-0,6$ \\
\hline $\mathrm{Na}$ & 10443 & 78 & $1674-33037$ \\
\hline $\mathrm{Nd}$ & 31 & 61 & $4-73$ \\
\hline $\mathrm{Rb}$ & 69 & 51 & $17-180$ \\
\hline $\mathrm{Sb}$ & 0,4 & 52 & $0,2-0,8$ \\
\hline $\mathrm{Sc}$ & 7 & 54 & $0,8-13$ \\
\hline $\mathrm{Se}$ & 0,5 & 60 & $0,2-1,4$ \\
\hline $\mathrm{Sm}$ & 5 & 65 & $1,0-12$ \\
\hline $\mathrm{Ta}$ & 0,8 & 44 & $0,1-2$ \\
\hline $\mathrm{Tb}$ & 0,4 & 57 & $0,1-0,9$ \\
\hline $\mathrm{Th}$ & 10 & 63 & $1-24$ \\
\hline $\mathrm{U}$ & 3 & 86 & $0,9-14$ \\
\hline $\mathrm{Yb}$ & 2 & 54 & $0,5-4$ \\
\hline $\mathrm{Zr}$ & 188 & 50 & $43-385$ \\
\hline & &
\end{tabular}

The correlation coefficient was also determined indicating that: a) the rare earth elements are strongly correlated between themselves and also with trace metals, $\mathrm{Fe}, \mathrm{Zr}$ and $\mathrm{Th} ; \mathrm{b})$ the elements $\mathrm{U}$ and $\mathrm{Th}$ are well correlated between themselves, Th is strongly correlated with all rare earth elements, trace metals and Fe; c) $\mathrm{U}$ is well correlated only with Cs and Ta, among the trace metals.

$\mathrm{Fe}$ is generally well correlated with all trace metals. Therefore, it can be used to normalise experimental results and to identify possible enrichments among the analysed elements. Since aluminium was not detected by NAA, iron was used to normalise the studied elements.

Although there are a lot of possible external sources of iron, the results obtained by using Fe as a normaliser showed good agreement for $\mathrm{Co}, \mathrm{Ce}, \mathrm{Cr}, \mathrm{Cs}, \mathrm{Eu}, \mathrm{La}, \mathrm{Lu}, \mathrm{Nd}, \mathrm{Sc}, \mathrm{Sm}$, $\mathrm{Ta}, \mathrm{Th}, \mathrm{Yb}$ and Zr. Slight enrichments were observed for As in points 17 and 19; for Se in points 7, 9, 16, and 17 and for $U$ in points 12 and 13. An explanation for $U$ enrichment may be the great concentration of organic matter.

Table 2 shows activity concentrations for $\mathrm{U}, \mathrm{Th},{ }^{226} \mathrm{Ra},{ }^{228} \mathrm{Ra},{ }^{210} \mathrm{~Pb}$ and ${ }^{40} \mathrm{~K}$ and activity ratios ${ }^{226} \mathrm{Ra} /{ }^{238} \mathrm{U}$ and ${ }^{228} \mathrm{Ra} /{ }^{232} \mathrm{Th}$.

Points 1, 2 and 3 presented concentrations for ${ }^{226} \mathrm{Ra}$ and ${ }^{228} \mathrm{Ra}$ above the mean value of the region, probably due to releases from stockpiled phosphogypsum originated in the 
phosphoric acid industries. This contamination is supported by the results obtained for the activity ratio ${ }^{226} \mathrm{Ra} /{ }^{238} \mathrm{U}$ and ${ }^{228} \mathrm{Ra} /{ }^{232} \mathrm{Th}$ in the same points, which were higher than usually expected due to the solubility of radium isotopes in estuarine systems (Gascoyne, 1982; Moore, 1981). This enrichment can also be seen when normalising the activity concentrations of $\mathrm{Ra}$ isotopes with iron concentration. The correlation coefficient analysis shows that $\mathrm{Ra}$ isotopes have a strong correlation with rare earth elements, $\mathrm{Fe}, \mathrm{Zr}$ and trace metals.

Table 2: Activity concentrations $(\mathrm{Bq} / \mathrm{kg})$ for $\mathrm{U}, \mathrm{Th},{ }^{226} \mathrm{Ra},{ }^{228} \mathrm{Ra},{ }^{210} \mathrm{~Pb}$ and ${ }^{40} \mathrm{~K}$ and activity ratios ${ }^{226} \mathrm{Ra} /{ }^{238} \mathrm{U}$ and ${ }^{228} \mathrm{Ra} /{ }^{232} \mathrm{Th}$.

\begin{tabular}{|c|c|c|c|c|c|c|c|c|}
\hline & $\mathbf{U}$ & Th & ${ }^{226} \mathrm{Ra}$ & ${ }^{228} \mathrm{Ra}$ & ${ }^{210} \mathrm{~Pb}$ & ${ }^{40} K$ & ${ }^{226} \mathrm{Ra} /{ }^{238} \mathrm{U}$ & ${ }^{228} \mathrm{Ra} /{ }^{232} \mathrm{Th}$ \\
\hline A 1 & $69 \pm 6$ & $79 \pm 4$ & $44 \pm 5$ & $77 \pm 6$ & $49 \pm 9$ & $379 \pm 30$ & $1,3 \pm 0,1$ & $0,98 \pm 0,05$ \\
\hline A 2 & $109 \pm 8$ & $96 \pm 5$ & $43 \pm 5$ & $73 \pm 6$ & $44 \pm 9$ & $392 \pm 32$ & $0,81 \pm 0,07$ & $0,76 \pm 0,04$ \\
\hline A 3 & $86 \pm 7$ & $60 \pm 3$ & $40 \pm 5$ & $59 \pm 6$ & $41 \pm 8$ & $546 \pm 39$ & $0,96 \pm 0,09$ & $0,99 \pm 0,06$ \\
\hline A 6 & $871 \pm 8$ & $37 \pm 2$ & - & - & - & - & - & - \\
\hline A 7 & $48 \pm 13$ & $15 \pm 1$ & - & - & - & - & - & - \\
\hline A 8 & $95 \pm 27$ & $44 \pm 4$ & $19 \pm 4$ & $25 \pm 5$ & $60 \pm 11$ & $430 \pm 38$ & $0,4 \pm 0,2$ & $0,6 \pm 0,1$ \\
\hline A 9 & $43 \pm 4$ & $32 \pm 2$ & $13 \pm \pm 3$ & $15 \pm 3$ & $37 \pm 7$ & $341 \pm 29$ & $0,6 \pm 0,1$ & $0,47 \pm 0,06$ \\
\hline$\overline{\text { A } 10}$ & $103 \pm 9$ & $44 \pm 2$ & $20 \pm 4$ & $29 \pm 4$ & $47 \pm 9$ & $418 \pm 34$ & $0,40 \pm 0,07$ & $0,66 \pm 0,05$ \\
\hline A 12 & $348 \pm 27$ & $77 \pm 4$ & $31 \pm 5$ & $36 \pm 5$ & $114 \pm 21$ & $486 \pm 39$ & $0,18 \pm 0,04$ & $0,47 \pm 0,04$ \\
\hline A 13 & $145 \pm 20$ & $41 \pm 2$ & $20 \pm 4$ & $24 \pm 4$ & $47 \pm 10$ & $428 \pm 31$ & $0,28 \pm 0,08$ & $0,58 \pm 0,06$ \\
\hline A 14 & $116 \pm 16$ & $42 \pm 2$ & $15 \pm 3$ & $20 \pm 3$ & $95 \pm 18$ & $370 \pm 30$ & $0,27 \pm 0,08$ & $0,48 \pm 0,05$ \\
\hline A 15 & $84 \pm 13$ & $34 \pm 2$ & $15 \pm 3$ & $16 \pm 4$ & $69 \pm 14$ & $315 \pm 31$ & $0,4 \pm 0,1$ & $0,47 \pm 0,08$ \\
\hline A 16 & $26 \pm 13$ & $10,2 \pm 0,4$ & $8 \pm 2$ & $10 \pm 3$ & $27 \pm 4$ & $189 \pm 21$ & $0,6 \pm 0,4$ & $1,0 \pm 0,1$ \\
\hline A 17 & $23 \pm 5$ & $4,5 \pm 0,2$ & $6 \pm 2$ & $8 \pm 3$ & $13 \pm 0$ & $186 \pm 20$ & $0,5 \pm 0,2$ & $1,8 \pm 0,2$ \\
\hline A 18 & $43 \pm 10$ & $29 \pm 1$ & - & - & - & - & - & - \\
\hline A 19 & $26 \pm 8$ & $11,0 \pm 0,4$ & - & - & - & - & - & - \\
\hline A 20 & $31 \pm 8$ & $21 \pm 1$ & - & - & - & - & - & - \\
\hline A 21 & $74 \pm 18$ & $41 \pm 2$ & $13 \pm 5$ & $23 \pm 6$ & $73 \pm 8$ & $377 \pm 40$ & $0,4 \pm 0,2$ & $0,6 \pm 0,1$ \\
\hline
\end{tabular}

For $U$ distribution, points located in the vicinity of the industrial area presented mean activity concentration of $117 \mathrm{Bk} / \mathrm{kg}$, whereas more distant points $(9,16,17,18,19$ and 20) presented concentrations below $50 \mathrm{~Bq} / \mathrm{kg}$, with mean value of $32 \mathrm{~Bq} / \mathrm{kg}$.

The results obtained for the correlation coefficients between Th and Ra-isotopes, $\mathrm{U}$ and $\mathrm{Ra}$ isotopes and organic matter and $\mathrm{Ra}$ isotopes show that points 1,2 and 3 present anomalous concentrations of Ra-isotopes and Th.

The correlation analysis for ${ }^{210} \mathrm{~Pb}$ showed that this element correlates with rare earth elements, trace metals and $\mathrm{Fe}$ and it seems to be enriched just in the areas with high organic matter content. ${ }^{40} \mathrm{~K}$ showed the same trend as ${ }^{210} \mathrm{~Pb}$.

\section{CONCLUSIONS}

The results obtained reflect the complexity of the region, however good correlation was observed between Fe concentration and $\mathrm{Co}, \mathrm{Ce}, \mathrm{Cr}, \mathrm{Cs}, \mathrm{Eu}, \mathrm{La}, \mathrm{Lu}, \mathrm{Nd}, \mathrm{Sc}, \mathrm{Sm}, \mathrm{Ta}, \mathrm{Th}$, $\mathrm{Yb}, \mathrm{Zr}$, and Ra-isotopes content. These results corroborate the already observed enrichment of ${ }^{226} \mathrm{Ra},{ }^{228} \mathrm{Ra}$ and $\mathrm{Th}$ in the surroundings of the phosphoric acid industries located in the region, both by the correlation analysis and by the iron normalisation. It can also be seen, that the organic matter content, in the estuary sediment, is a powerful trap for nuclides $\mathrm{U}$ and ${ }^{210} \mathrm{~Pb}$.

\section{ACKNOWLEDGMENTS}


This work was supported by Fundação de Amparo à Pesquisa do Estado de São Paulo - FAPESP, under fellowship contract 99/06952-4 and by Conselho Nacional de Desenvolvimento Científico e Tecnológico - CNPq, grant 300835/95-7. The samples analysed were provided by CETESB (Companhia de Tecnologia de Saneamento Ambiental).

\section{BIBLIOGRAPHY}

Custhall, N.H., Larser, I. L., and Olsen, C.R. . 1983 . Direct analysis of ${ }^{210} \mathrm{~Pb}$ in sediment samples: self-absorption corrections. Nuclear Instruments and methods 206: 309312

Elbaz-Poulichet, F. and Dupuy, C. 1999 Behavior of rare earth elements at the freshwater - seawater interface of two acid mine rivers: the Tinto and Odiel (Andalucia, Spain). Appl. Geochem. 14: 1063 - 1072.

Gascoyne, M. 1982. Geochemistry of the Actinides. In: Ivanovich, M and Harmon, R. S. Uranium Séries Disequilibrium: Applications to Environmental Problens. Oxford, Clarendom Press, p. $33-55$.

InterWinner Spectroscopy Program Family Version 4.1 (release $1^{\text {st }}$ of June 1998) marca Eurisys Mesures.

Kralik, M., 1999 A rapid procedure for environmental sampling and evalution of polluted sediments. Appl. Geochem. 14: $807-816$.

McNabb, G. J.; Kirk, J. A . e Thompson, J. L., 1979, Radionuclides from phosphateore-processing plants: the enviromental impact after 30 years of operation. Health Phisics, 37: $585-587$.

Moore, M. S., 1981, Radium isotopes in the Chesapeake Bay. Estuar. Coast Shelf. Sci. 12: $713-723$.

Periáñez, R. e Garcia-León, M., 1993, Ra-isotopes around a phosphate fertilizer complex in an estuarine system at the southwest of Spain. Jour. Of Radioanal. And nucl. Chem., 172: $71-79$.

Silva, P. S. C., Mazzilli, B.P. e Favaro, D. I. T., 2001, Estudo dos Elementos Terras Raras em Sedimentos do Estuário de Santos e São Vicente. VIII Congresso Brasileiro de Geoquímica, Curitiba, Accepted for publication. 